dissection I excised from this marked-out area all the tissue lying superficially to the sclera. The surface thus exposed on the globe of the eye was a comparatively large one, but it healed gradually and satisfactorily and became completely covered with new epithelium without the formation of any cicatricial contraction. On Dec. 16th, 16 days later, the eye was quiet and the banaage and dressings were left off. Three days afterwards, when I was examining the eyes minutely by oblique illumination, I for the first time saw on the margin of the upper eyelid of the right eye (the eye which had been affected) a delicate fine eyelash which was inverted and rubbed against the surface of the globe, almost exactly at the point tormerly occupied by the tumour. The eyelash was epilated and has not made any further appearance. Whether this had existed previously and taken part in the causation of the tumour or in its recurrence are questions which must remain undecided. The offending eyelash was an exceedingly fine one and could only be seen when examined through a lens of high magnifying power.

A careful histological examination of the recurrent growth was made after its removal and the following report was obtained: "After fixation in alcohol sections were made, placed in carbolic thionin, and stained. Result of examination.-Fibro-myoma. The cells are elongated, with rodshaped rectangular nuclei, filling all the stroma which is fine, ribbon-like, and very crowded. At the periphery there are some vessels containing blood and some groups of microbes (probably ulceration)."

I understand that a similar result was yielded by microscopical examination of the tumour which was originally removed. Since the removal of the bandage and dressings over the eye no application or local medication has been employed, and the eye presents no indication, except on most minute and careful observation, of its recent condition and there is every reason to believe that permanent relief has now been obtained.

Manchester-square, W.

NOTE ON A CASE OF SO-CALLED "SPONTANEOUS FRACTURE" OF THE FEMUR FROM SECONDARY MALIGNANT DISEASE WITH SUBSEQUENT FIRM BONY UNION.

By T. Morrell Thomas, M.D., M.S. LOND., F.R.C.S. ENG., HONORARY SURGEON TO THE NEWPORT AND MONMOUTHSHIRE HOSPITAL;

AND

B. G. Fiddian, M.B., B.S. Lond.,

RESIDENT MEDICAL OFFICER, NEWPORT AND MONMOUTHSHIRE HOSPITAL.

WE record the following case on account of its extreme rarity. According to Mr. S. Boyd, in his article on fractures in Treves's " System of Surgery," there are only some four or five on record. The patient, a married woman, aged 47 years, had her left breast removed for scirrhus 14 months prior to the date of fracture. The scirrhus was one of rapid growth, was fairly advanced, fixed to the pectoralis major, and there was palpable gland implication. She had had increasing weakness of both legs (? due to advancing cachexia) for six months prior to fracture and for the same length of time had "rheumatic" pains in both thighs. As these pains were more definitely localised over the future site of fracture it seems possible that they were due to implication of nerve fibrils in the growth. On Dec. 6th, 1902, while the patient was in the act of stooping to pick something up off the floor the left thigh suddenly snapped. She was admitted to the Newport and Monmouthshire Hospital two days after the accident and remained there till she died. On admission she was found to have sustained a fracture of the left femur at the junction of the upper and middle thirds. The limb was put up on a McIntyre splint. Thinking an ununited fracture was inevitable no extension was applied to the limb; we thought it would give her needless pain, so the limb was merely allowed to rest on the splint, being frequently taken down to guard against splint sores. Not much attention was paid to the condition at the site of fracture for the reason mentioned above. On Jan. 26th, 1903, however, seven weeks after the accident, an examination of the part showed that union had taken place. There was at this time a recurrence at the site of the removal of the breast as well as a mass in the liver. The patient got steadily weaker and died from secondary malignant disease on Feb. 15th

Neoropsy. - The site of fracture was cut down on and the upper half or so of the femur was removed en bloc. Such firm union of the fragments was found that they could not be torn apart even on the exertion of considerable manual force A mass of cancerous growth was found wrapping the upper third of the femur loosely round and eroding it at the site of fracture-i.e., the upper end of the lower fragment and lower end of the upper-but the rest of the femur was uneroded. The conjoined mass of callus and malignant tissue cut like a scirrhus but with a gritty sensation at parts. It apparently extended from a chain of malignant glands which passed down from behind Poupart's ligament and seemed to have acquired an attachment to the periosteum. There was distinct overlapping of the fragments and to this union seems to have been due, for by this means unimplicated portions of periosteum were brought into apposition, not the diseased extremities of the fragments. A paring was taken from the mass in the neighbourhood of the end of one of the fragments and sent to the Clinical Research Association for microscopical examination. The report was as follows: "The tissues consist of periosteum and young bone with some adjacent fat and cellular tissue. They are all thickly infiltrated with narrow lines of scirrhus carcinoma." Oc curring as this case did subsequently to removal of a rapidly growing scirrhus, the result being firm union of the fragments and the condition of overlapping suggesting a possible explanation of departure from the sequence of events which is usual in such cases, we have thought it right that the case should be published.

\section{NOTE ON A CASE OF TRANSPOSITION OFETHE VISCERA.}

By EdWARD LIDDON, M.D. EDIN.,

CONSULTING PHYSICIAN TO THE TAUNTON AND SOMERSET HOSPITAL.

THE interesting case reported by Dr. William Hartland in THE LANCET of April 9th, p. 1017, reminds me of a very similar instance that came under my notice some years since when holding the appointment of honorary physician to the Taunton and Somerset Hospital.

A young man, aged 19 years, was admitted with pneumonia of the left base, and on examination it was discovered that all the viscera were transposed, the heart and spleen to the right, whilst the liver lay beneath the left ribs. He was a source of much interest to myself and to all $\mathrm{my}$ colleagues whilst he remained in the hospital. He made a good recovery from his illness and went into service near Brighton and for some years continued in good health. He had never been robust and always carried a "high colour," but until his attack of pneumonia he had suffered from no serious illness. His father died from some form of heart trouble; his brother, who had been a groom in $\mathrm{my}$ stable, was healthy and possessed no malformation. It was from him that I heard of my hospital patient's well-doing for some years after he left this neighbourhood.

Taunton.

Centenary of the Russian Medical Council.On April 22nd the Russian Medical Council completed its 100th year dating from its first session. It was founded on Dec. 31st, 1803, by order of the Minister of the Interior, Count Kotchubye, and was formally opened on April 9th, 1804. At the first gathering of the Council the Sovereign order for its constitution was read and a committee of five members was chosen to draw up the rules, duties, and prerogatives of the Council. It is proposed to celebrate its first centenary in a special manner on April 9th, 1905.

Hospital for EpIlepsy and Paralysis and OTHER DISEASES OF THE NERVOUS SYSTEM.-The committee of management announces that the annual meeting will be held at the New Hospital, 4, Maida-vale (near the end of St. John's Wood-road), at 4.30 P.M., on Thursday, May 5th, at which hour Mr. Charles Drummond, the treasurer, will take the chair. The annual report and financial statement for the year 1903 will be presented. After the meeting the New Hospital, now in full work, will be open for the infpection of throe who attend this meeting. 